Y.C. Wong*, R.X. Ang

\title{
Study of calcined eggshell as potential catalyst for biodiesel formation using used cooking oil
}

https://doi.org/10.1515/chem-2018-0127

received May 15, 2018; accepted July 21, 2018.

Abstract: Eggshells were utilized as a cost effective catalyst to assist in biodiesel formation. Eggshells were calcined using different calcination conditions such as temperature and time. The eggshells underwent calcination under $1000{ }^{\circ} \mathrm{C}$ in which calcium carbonate was completely converted into calcium oxide under open air conditions. The calcined eggshell catalyst was characterized by X-ray diffraction (XRD). Then the eggshell derived $\mathrm{CaO}$ catalyst was subjected to transesterification of used cooking oil (UCO). The parametrics in the transesterification of used cooking oil such as a methanol to oil ratio, weight of catalyst and reaction temperature were evaluated. The optimum result exhibited a 4:1 methanol to oil ratio, $2 \mathrm{wt} \%$ catalyst, and a $65^{\circ} \mathrm{C}$ reaction temperature within two hours. Pure calcined $\mathrm{CaO}$ acted as the control of the experiment that was subject to the most optimum eggshell derived catalyst transesterification conditions. The catalytic activity for both the pure calcined $\mathrm{CaO}$ and the calcined eggshell derived catalyst were comparable. The biodiesel formation was identified by gas chromatography mass spectrometry (GC-MS).

Keywords: Calcination; eggshell; Calcium oxide; Transesterification; Used cooking oil.

\section{Introduction}

The continuous increase in crude oil prices and the depletion of petroleum reserves, has aroused researchers

\footnotetext{
* Corresponding author: Y.C. Wong, Faculty of Bioengineering and Technology, Universiti Malaysia Kelantan, Jeli Campus, Locked Bag 100, 17600 Jeli, Kelantan, Malaysia; Faculty of Agro Based Industry, Universiti Malaysia Kelantan, Jeli Campus, Locked Bag 100, 17600 Jeli, Kelantan, Malaysia, E-mail: yeeching@umk.edu.my R.X. Ang: Faculty of Agro Based Industry, Universiti Malaysia Kelantan, Jeli Campus, Locked Bag 100, 17600 Jeli, Kelantan, Malaysia
}

to develop alternative ways to replace gas-derived fuels. Biodiesel has appeared as an alternative fuel to replace gas-based fuels [1]. Costs of raw materials, usually refined vegetable oil, add to the production cost [2]. As a consequence, the ideas of used cooking oil (UCO) as raw material feedstock are generated [3]. Many scientists applied homogenous alkaline catalysts in biodiesel production due to the low cost and high availability. $\mathrm{CaO}$ is one of widely-used catalysts due to its abundant availability in nature, its high activity and low cost [4].

During the past few years, researchers have begun focusing on the regeneration of waste materials such as eggshells as useful substances. Eggshell waste comprises a big portion of food industrial waste as eggs are a daily diet in many countries. For instance, dried eggs, liquid eggs, and frozen eggs are the diversified form of egg products that are found in markets. An egg is considered a relatively cheap food that provides complete nutrition with protein sources $(6 \mathrm{~g})$, unsaturated fatty acids (10\%), essential minerals and vitamins such as A, D [5]. The egg industry is a leader is one of the major sectors iof the world food market.

According to literature, there are many added-values derived from waste eggshells such as calcium phosphate bioceramics [6], hydroxyapatite(HA) as implanted constituents [7], and as absorption of dyes[8]. Waste eggshells consist of a majority of calcium carbonate compounds, nearly $95 \%$ of which are suitable as activated heterogeneous catalysts used in biodiesel production [9]. Calcium oxide components can be generated from eggshell waste after calcination and used in the transesterification process.

This study addresses the following objectives: one is to synthesize a potential catalyst from eggshell waste and to identify most effective calcination conditions for the calcined eggshells derived catalyst. The second objective is to determine the effect of the methanol to oil ratio, the weight of the catalyst and the reaction temperature using the most effective calcined eggshell conditions derived catalyst to form biodiesel.

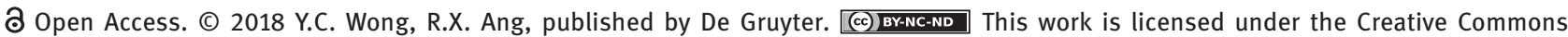
Attribution-NonCommercial-NoDerivatives 4.0 License. 


\section{Materials and methods}

\subsection{Catalyst preparation}

The wasted chicken eggshells were collected by selling Char Keow Teow stall. The eggshells were peeled from their membranes to remove any interference substances and impurities such as organics materials. After that, chicken eggshells were rinsed three times with tap water. Then, the eggshells were dried in a hot air oven for 24 hours at $60^{\circ} \mathrm{C}[9]$.

Next, the dried eggshells were pulverized into fine powder using a blender. The powder was sieved to constant sizes such as $0.045 \mathrm{~mm}$ by using a buger sieve with the help of an automatic sieve shaker. Next, eggshell powders were transferred into a furnace to generate calcium oxide. The eggshells, potential catalysts were cooled down and placed in a desiccator to reduce the probability of reacting with any humidity and $\mathrm{CO}_{2}$ in the air. The acidic particles like $\mathrm{CO}_{2}$ and $\mathrm{H}_{2} \mathrm{O}$ are considered poisonous to the catalyst's active site [10] . Hence, the calcined eggshells needed to be kept in the desiccator to avoid contact with those particles. Additionally, the silica gel needed to have a blue color instead of a pink color. Blue silica gel is made up of cobalt chloride, and it will turn pink when saturated with water and cannot absorb any moisture.

Different conditions were applied to synthesize eggshells as potential catalysts. For instance, eggshells calcination using a muffle furnace under $800{ }^{\circ} \mathrm{C}$ for 4 hours (Condition 1), eggshells calcination using a tube furnace under $1000{ }^{\circ} \mathrm{C}$ for two hours with nitrogen gas flow (Condition 2), and eggshells calcination using a tube furnace under $1000{ }^{\circ} \mathrm{C}$ for two hours without nitrogen gas flow (Condition 3).

Pure calcium oxide acted as a experimental control and was subjected to the same calcination conditions.

\subsection{Characterization of catalyst using X-Ray Diffraction (XRD)}

In order to prove the potential of eggshells as catalysts, $\mathrm{XRD}$ analysis was conducted in the uncalcined or calcined chicken eggshell powder. Apart from that, pure calcium oxides either uncalcined or calcined were observed in XRD.

With the $2 \theta$ range from $10^{\circ}$ to $90^{\circ}$, the XRD powder diffraction analysis of the samples were carried out using $\mathrm{Cu} \mathrm{K- \alpha}$ radiation with a $2^{\circ} /$ min scanning speed and a $0.04^{\circ}$ step size[9].
The components found in the respective calcination methods were identified. The diffraction pattern was determined by referring to the International Centre for Diffraction Data (ICDD) using the powder diffraction file PDF-2 Release 2014 as a reference database.

\subsection{Pre-treatment of used cooking oil}

Used cooking oil was collected from the cafeteria of the Jeli Campus at the University of Malaysia, Kelatan. First, dispersed particles and any residues in the oil were filtered using cheese cloth. Then, centrifugation was employed to discard any impurities or fat sediment. Then the oil was filtered using filter paper to get a better quality oil. Next, oil was heated at $110^{\circ} \mathrm{C}$ for 50 minutes to evaporate any trace amount of moisture in a $2 \mathrm{~L}$ beaker using a hot plate with magnetic stirrer [11].

\subsection{FFA identification}

Total quantities of FFA in the oil samples were identified using the titration method [12] before any reactions were carried out. First, the amount of 0.5 grams of potassium hydroxide (KOH) was weighted and dissolved into $500 \mathrm{~mL}$ of distilled water in a $1 \mathrm{~L}$ beaker. The potassium hydroxide solution $(\mathrm{KOH})$ was then transferred into a burette.

$1 \mathrm{~mL}$ of used cooking oil was dissolved into $10 \mathrm{~mL}$ of isopropyl alcohol in a $50 \mathrm{~mL}$ beaker. The beaker consisted of used cooking oil. The isopropyl alcohol was heated in a water bath for 15 minutes at $60{ }^{\circ} \mathrm{C}$. Color changes were observed ranging from a dark brown to a plain yellowish solution as the used cooking oil slowly dissolved into isopropyl alcohol.

The dissolved solution of used cooking oil together with isopropyl alcohol was then transferred into a 500 mL Erlenmeyer flask. Then two drops of phenolphthalein were added. Potassium hydroxide $(\mathrm{KOH})$ was added slowly from the burette into the alcohol-oil mix solution, and the solution mixture was swirled gently. The light pink color appeared which lasted for 10 seconds revealing the endpoint measurement and the final volume of potassium hydroxide $(\mathrm{KOH})$ which was then recorded. The experiment was repeated three times to collect the average titration value.

The calculation formula for the FFA $\%$ from a titration value is shown in Equation 1

$$
\mathrm{FFA} \%=(\mathrm{t}-\mathrm{b}) \times \mathrm{N} \times 28.2 / \mathrm{v}---
$$


t indicates amount $(\mathrm{mL})$ of titration sample

b indicates amount $(\mathrm{mL})$ of the blank sample

$\mathbf{N}$ indicates normality $(\mathrm{N})$ of the titration sample

$\mathbf{v}$ indicates quantity ( $\mathrm{g}$ ) of the oil sample

\subsection{Synthesis of biodiesel through transesterification}

The reaction took place using a $250 \mathrm{~mL}$ Erlenmeyer flask, a magnetic stirrer, a reflux condenser, a hot plate, a thermometer, and a $1 \mathrm{~L}$ beaker which acted as a water bath. First, the calcined eggshell catalyst was mixed with methanol for one hour to produce calcium methioxide.

$50 \mathrm{~mL}$ of used cooking oil was then transferred accordingly into a new Erlenmeyer flask. The calcium methioxide solution which had stirred for one hour was poured into the oil. The content was refluxed under magnetic stirring for two hours in a closed vessel to avoid the evaporation of methanol[13]. The reaction duration was fixed at hours due to the longer reaction time, there will be hindrance to the catalyst hence suppress the biodiesel yield [14].

Three parameters were studied using calcined eggshells as a potential catalyst. Those were the weight of the calcined eggshell catalyst (1.0 wt \%, 2.0 wt \%, $3.0 \mathrm{wt} \%$, $4.0 \mathrm{wt} \%$, $5.0 \mathrm{wt} \%)$, the reaction temperature $\left(35^{\circ} \mathrm{C}, 45^{\circ} \mathrm{C}\right.$ , $55^{\circ} \mathrm{C}, 65^{\circ} \mathrm{C}$ ) and the methanol to oil ratio(1:1, 2:1, 3:1, 4:1, 5:1). The reaction temperature was set below $65^{\circ} \mathrm{C}$ due to the boiling point of methanol being at $65^{\circ} \mathrm{C}$. Methanol starts to bubble as it boilswhich would hinder the threephase interface reaction (methanol, $\mathrm{CaO}$, and oil) to take place[15].

\subsection{Separation and purification}

After transesterification, the solution mixture underwent a gravity separation overnight in a separatory funnel. After that, the separation was complete with densities and the upper layer as methyl ester, methanol and the bottom layer as glycerine[16].

The upper layer was subjected to centrifugation at $6000 \mathrm{rpm}$ for 15 minutes to remove the residue catalyst; meanwhile the bottom layer was withdrawn and discarded. Next, warm water was required to purify the sample product by rinsing out the impurities such as methanol, glycerol, $\mathrm{CaO}$, and soap. Warm water was introduced slowly to avoid emulsion and soap formation [17]. The washing of biodiesel was stopped until the water appeared transparent and clear compared to the cloudy yellowish solution from previous rinsings.

Then, the sample product was subjected to heating to evaporate the residual moisture. Finally, the biodiesel was cooled to room temperature and sealed with a parafilm kept in a dark place.

\subsection{Analysis of fatty acid and methyl esters content}

The fatty acid component of used cooking oil and its methyl esters content of sample products were carried out using Agilent $7890 \mathrm{~N}$ gas chromatography with an Agilent 7693 mass selective detector. The capillary column applied had a $30 \mathrm{~m}$ x $0.25 \mathrm{~mm}$ dimension i.d $0.25 \mathrm{~lm}$ film thickness (Agilent Technologies) with HP- 5MS (5\% phenyl methylsiloxane).

The gas chromatograph setting was achieved accordingly using a fatty methyl ester(FAME) procedure. The molecular mass was set at a range from $30-300$. The desired compounds were matched according to the peak and retention time based on the NIST (National Institute of Standards and Technology) library.

\section{Results and Discussion}

\subsection{Conversion of eggshell into potential catalyst}

\subsubsection{XRD pattern of different calcination methods of eggshell samples}

XRD analysis was carried out to identify the component and crystallinity of eggshell components. Figure 1 represented an XRD pattern of eggshells before calcination and after calcination at two different temperatures ranges, that were $800^{\circ} \mathrm{C}$ and $1000^{\circ} \mathrm{C}$ and with two different conditions such as with closed air, open air and with nitrogen flow or without nitrogen flow.

Based on the pattern of the X-ray diffraction on raw eggshells, only calcium carbonate existed in the raw eggshell powder before calcination (A). This depicted that calcium carbonate was the prime compound in the eggshell. Calcium carbonate was the major compound for the eggshells after close atmosphere calcination under temperature $800^{\circ} \mathrm{C}$ (B) as observed in figure 1. After closed atmosphere calcination at $800^{\circ} \mathrm{C}(\mathrm{B})$, the intensity 


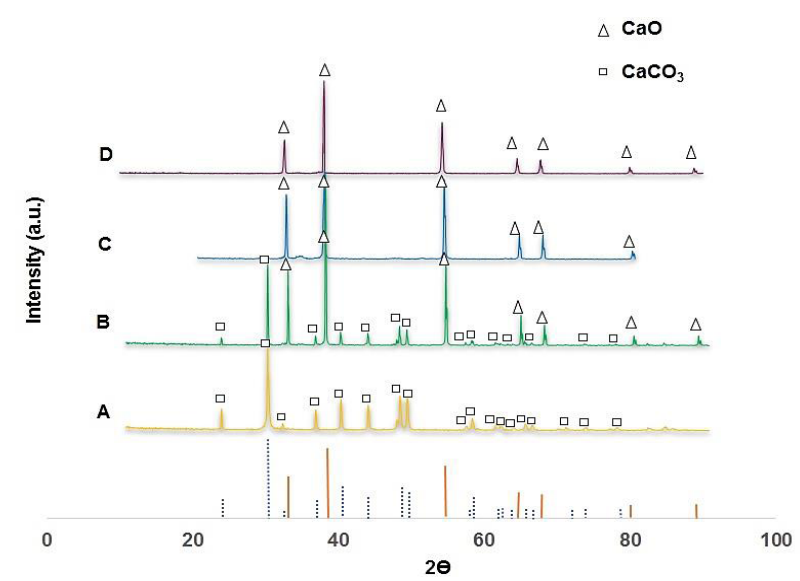

Figure 1: XRD pattern of samples of eggshell (A) eggshell before calcination, (B) eggshell with $800^{\circ} \mathrm{C}$ close atmosphere calcination, (C) eggshell with $1000^{\circ} \mathrm{C}$ nitrogen gas flow calcination, (D) eggshell with $1000^{\circ} \mathrm{C}$ open air calcination

of calcium carbonate was slightly reduced compared to before calcination and some of calcium oxide phases were appeared.

The intensity of the calcium carbonate for calcination at $800^{\circ} \mathrm{C}(\mathrm{B})$ changed compared to the uncalcined eggshells which was due to the calcium carbonate gradually transforming into calcium oxide[15]. A similar study demonstrated that the calcium carbonate did not completely convert into calcium oxide during the $800^{\circ} \mathrm{C}$ calcination process[18].

A calcium oxide peak only appeared after calcination at $1000^{\circ} \mathrm{C}$ with nitrogen gas flow (C) and in open air (D). This was due to the high thermal transition that occurred in the eggshells causing complete decomposition of the calcium carbonate into calcium oxide which occurred at $1000^{\circ} \mathrm{C}$.

The XRD pattern for both the open air calcined eggshells at $1000^{\circ} \mathrm{C}(\mathrm{D})$ and the nitrogen gas flow calcined eggshells at $1000^{\circ} \mathrm{C}$ (C) showed identical and highly crystallite clear peaks. The crystallite size of eggshells after calcination under $1000^{\circ} \mathrm{C}$ higher compared calcination under $800^{\circ} \mathrm{C}[19]$.

The calcination of eggshells for two hours at $800^{\circ} \mathrm{C}$ , the major phase being $\mathrm{CaCO}_{3}$ and the minor phase being $\mathrm{CaO}[20]$, showed similarities with this study. It was reported that $\mathrm{CaO}$ acted as a major component after calcination at $900^{\circ} \mathrm{C}$ for four hours. However, one of the researchers concluded that the best calcination temperature for eggshells waste was above $800^{\circ} \mathrm{C}$ for two hours and went on to report that the eggshell was calcined at $700^{\circ} \mathrm{C}$ for two hours and contained $\mathrm{CaO}$ as the minor phase and $\mathrm{CaCO}_{3}$ as the major phase[9].

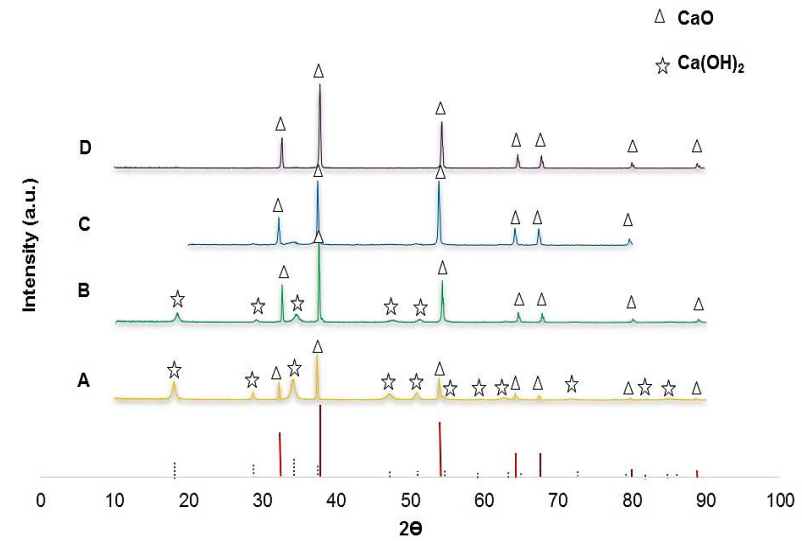

Figure 2 :XRD pattern of samples of Pure $\mathrm{CaO}(\mathrm{A})$ Pure $\mathrm{CaO}$ before calcination, (B) Pure $\mathrm{CaO}$ with $800^{\circ} \mathrm{C}$ close atmosphere calcination, (C) Pure $\mathrm{CaO}$ with $1000^{\circ} \mathrm{C}$ nitrogen gas flow calcination,(D) Pure $\mathrm{CaO}$ with $1000^{\circ} \mathrm{C}$ open air calcination

The calcination of the eggshell waste within the two to four-hour timeframe found the catalyst activities comparative to the transesterification process[21]. Extending the calcination timeframewould diminish the catalyst and surpress the active site whereby dropping the catalytic activity of the eggshell in transesterification. Therefore, it was suggested that the timeframe should not exceed 4 hours accordingly with the different calcination temperature.

\subsubsection{XRD pattern of different calcination methods of Pure $\mathrm{CaO}$ samples}

The XRD analysis was carried out to identify the pure calcium oxide component and to determine whether it had potential in becomingva catalyst without calcination, or calcination under different conditions. Figure 2 displays an X-ray diffractogram of pure calcium oxide before calcination, and pure calcium oxide after being subjected to different calcination conditions.

Based on the pattern of the X-ray diffraction of pure calcium oxide before calcination (A), two main components appeared to include calcium oxide and calcium hydroxide. The presence of calcium hydroxide was probably due to the uptake of moisture from the surrounding environment. This indicated that the pure calcium oxide should be subjected into in order to get rid other than calcium oxide component before carried on with transesterification process.

However, after calcination at $800^{\circ} \mathrm{C}(\mathrm{B})$, the calcium oxide peak appeared with high crystallinity and exhibited 
a lesser calcium hydroxide component than before calcination (A). However, calcium hydroxide did not fully convert into calcium oxide under calcination at $800^{\circ} \mathrm{C}$ (B). Thus, this indicated that the calcium oxide transformation required a higher temperature or longer calcination timeframe to completely remove the moisture content in $\mathrm{CaO}$.

As depicted from figure 2, the calcium oxide peak only appeared after calcination at $1000^{\circ} \mathrm{C}$ with a nitrogen gas flow (C) and with open air (D). This showed that the calcination at a higher temperature, but shorter time could help eliminate the water content in $\mathrm{CaO}$.

The XRD pattern for both open air calcined eggshells at $1000^{\circ} \mathrm{C}(\mathrm{D})$ and nitrogen gas flow calcined eggshells at $1000^{\circ} \mathrm{C}$ (C) showed high crystallite. The method for the open air calcined eggshell at $1000^{\circ} \mathrm{C}$ (D) was selected to make the potential catalyst as it could be achieved at a reduced cost compared to the nitrogen gas method and the cost for purchasing).

\subsection{Optimization of transesterification using calcined eggshell derived catalyst}

\subsubsection{Effect of methanol to oil ratio towards biodiesel formation}

A different methanol to oil molar ratio in this study was investigated from 1:1 to 5:1 as other factors remained constant. The reaction took place at a temperature of under $65^{\circ} \mathrm{C}$ for two hours, and used a $3 \mathrm{wt} \%$ calcined eggshell catalyst and $50 \mathrm{ml}$ of used oil.

Figure 3 depicted that the methanol to oil ratio of 1:1 to 5:1, biodiesel yield increase from $2 \mathrm{ml}$ to $4 \mathrm{ml}$. Initially, the methanol to oil molar ratio from 1:1 to 2:1 did not have any further change, it stagnated at $2 \mathrm{ml}$ of biodiesel yield.

However, the volume of biodiesel gradually increased from $2 \mathrm{ml}$ to $4 \mathrm{ml}$, from 2:1 to 4:1 of methanol to oil ratio respectively. As the methanol volume increased so did the biodiesel yield due to calcium methioxide, $\mathrm{Ca}\left(\mathrm{CH}_{3} \mathrm{O}\right)_{2}$ that formed during the pre-treatment of the calcium oxide with methanol before transesterification. This triggered the reaction equilibrium to shift to the right. Calcium methioxide can boost the reaction between oil and methanol [21].

The biodiesel yield no longer increased and stayed at $4 \mathrm{ml}$ for the 4:1 to 5:1 methanol to oil ratio. This could be ascribed to the excess of methanol preventing the gravity separation of methyl ester and glycerol fragment into two phases [14]. Researchers demonstrated that the higher methanol to oil ratio would promote a better FAME yield.

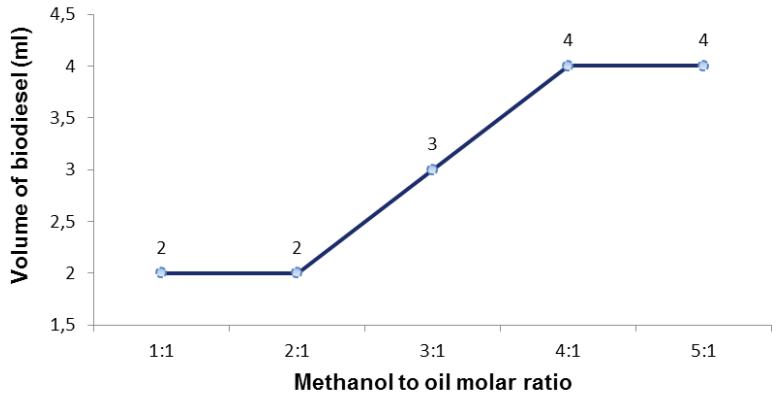

Figure 3:The effect of different methanol to oil ratios on the transesterification of used cooking oil. Conditions: reaction time of 2 hours, reaction temperature of $65^{\circ} \mathrm{C}$, catalyst weight of $3 \mathrm{wt} \%$.

However, the further increment in the methanol to oil ratio based on the system, caused the transesterification process to be reversible. The glycerol residues would shift the equilibrium to the left and hence the FAME yield would drop [22].

The biodiesel yield was relatively low compared to other studies; this was probably due to the slightly higher FFA content from used cooking oil. The biodiesel yield was highly related to the FFA content [23]. Researchers suggested that the way to maximize the methyl esters yield was to reduce the FFA content to $2 \%$ before carry on with transesterification.

\subsubsection{Effect of catalyst concentration towards biodiesel formation}

The effect of catalyst concentration, varying quantities from $1 \mathrm{wt} \%$ to $5 \mathrm{wt} \%$ according to the weight of initial used cooking oil towards the biodiesel formation were investigated. The reaction took place at a temperature below $65^{\circ} \mathrm{C}$ for two hours, and used $150 \mathrm{ml}$ methanol(4:1) and $50 \mathrm{ml}$ used oil. The outcomes were revealed in figure 4.

From figure 4, the conversion rate was identified to be slightly accelerated from $1 w t \%$ to $2 \mathrm{wt} \%$ of catalyst concentration that was from $3 \mathrm{ml}$ to $4 \mathrm{ml}$. This result described that the increment in weight of the catalyst boosted the contact between the reactant and the catalyst[15]. The more the catalyst used, the faster the reaction due to the faster collision between reactants molecules.

However, the for the further increase of catalyst concentration from $2 \mathrm{wt} \%$ to $3 \mathrm{wt} \%$, volume of biodiesel drops from $4 \mathrm{ml}$ to $3 \mathrm{ml}$, following by no any fluctuation in biodiesel volume for catalyst concentration of $4 \mathrm{wt} \%$ and $5 \mathrm{wt} \%$. 


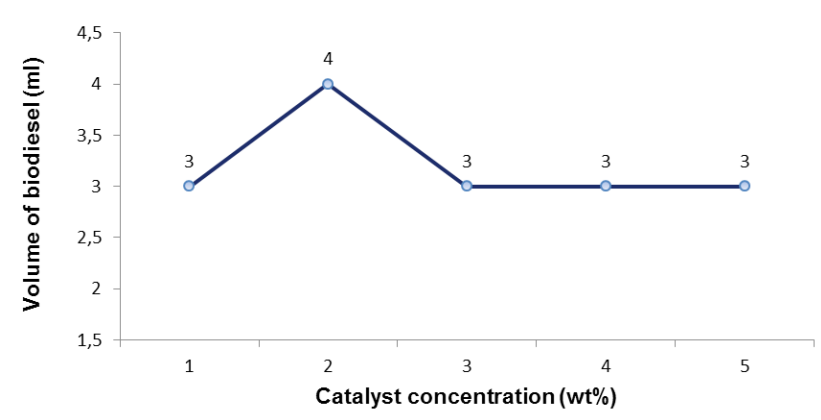

Figure 4: The effect of different catalyst concentrations on the transesterification of used cooking oil. Conditions: reaction time of 2 hours, reaction temperature of $65^{\circ} \mathrm{C}$, methanol to oil ratio $4: 1$.

The drop in biodiesel yield was due to the FFA and the water residue in used cooking oil which tended to react and cause soap formation during the transesterification process. The free fatty acids reacted with the alkaline catalyst that lead to saponification. Saponification depleted the alkaline catalyst inevitably lowering the effectiveness of the catalyst, hence collecting a lower biodiesel yield [15].

In addition, as the $\mathrm{CaO}$ used more, the leaching process from the $\mathrm{CaO}$ catalyst increased, resulting in more of the $\mathrm{CaO}$ to react with FFAs whereby turning into calcium soap during the purification process. Besides, there were certain amounts of biodiesel to form an emulsion during the washing process wherebylowering its yield. The amount of catalyst use was increased.[24].

\subsubsection{The reaction temperature profile towards biodiesel formation}

The reaction temperature was set higher than the room temperature such as $35^{\circ} \mathrm{C}, 45^{\circ} \mathrm{C}, 55^{\circ} \mathrm{C}$, and $65^{\circ} \mathrm{C}$. The reaction took place using $150 \mathrm{ml}$ (4:1) methanol and $50 \mathrm{ml}$ used oil and $3 \mathrm{wt} \%$ catalyst concentration for two hours.

Figure 5 revealed that a slightly increase in temperature resulted in a higher biodiesel yield. At the beginning, the FAME yield was $3 \mathrm{ml}$ although the temperature increased from $35^{\circ} \mathrm{C}$ to $45^{\circ} \mathrm{C}$. This result showed that the low temperature did not favor a transesterification reaction. However, the additional increase of the reaction temperature from $45^{\circ} \mathrm{C}$ to $55^{\circ} \mathrm{C}$, lifted the volume of biodiesel from $3 \mathrm{ml}$ to $4 \mathrm{ml}$, subsequently no variation in the biodiesel volume was noted for a further increase of the reaction temperature from $55^{\circ} \mathrm{C}$ to $65^{\circ} \mathrm{C}$.

The further increase in biodiesel volume in alignment with the increase of the reaction temperature attributed to the solubility of the methanol towards triglycerides.

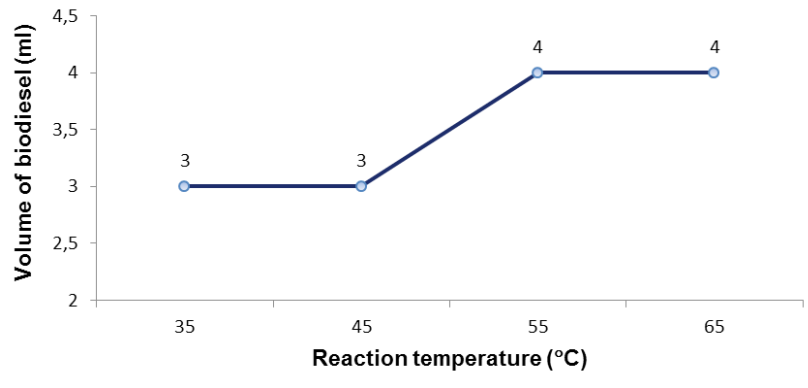

Figure 5: The effect of different temperatures on the transesterification of used cooking oil. Conditions: reaction time of 2 hours, methanol to oil ratio 4:1, catalyst weight 2 wt $\%$.

However, increasing the reaction temperature further did not influence the biodiesel yield [25]. This is due to the boiling point of methanol at nearly $68^{\circ} \mathrm{C}$, the evaporation of methanol and the bubbling which would adversely hinder a reaction if the temperature were higher than $65^{\circ} \mathrm{C}[15]$.

\subsection{Product analysis using GC-MS}

Figure 6,7 and 8 show the chromatograms of the initial used cooking oil after transesterification using calcined eggshells and after transesterification using calcined $\mathrm{CaO}$. The chromatogram peaks exhibit the outcome of separation of particular compounds, which were detected by the gas chromatogram. Chromatograms of natural derived $\mathrm{CaO}$ from calcined eggshells and pure calcined $\mathrm{CaO}$ after transesterification display some similarity in terms of peak shape and size as revealed in figures $7 \& 8$. The chromatogram peak and its components using calcined eggshells and using calcined pure $\mathrm{CaO}$ are exactly the same in table $1 \& 2$.

There are four methyl ester components in both chromatograms such as methyl tetradecanoate, hexadecanoic acid, methyl ester, 9-Octadecenoic acid, methyl ester, and 5,8,11,14-Eicosatetraenoic acid, methyl ester.

Besides, with the aid of mass spectrum, the selection of resemble mass to charge ratio of each possible compounds could be done more precisely. The desired compounds were selected based on the NIST library that comprises a database of mass spectra. The mass spectrum and its respective structure are displayed in used cooking oil, oil after transesterification using calcined eggshells and oil after transesterification using calcined $\mathrm{CaO}$ are displayed in figure $9 \& 10$. 


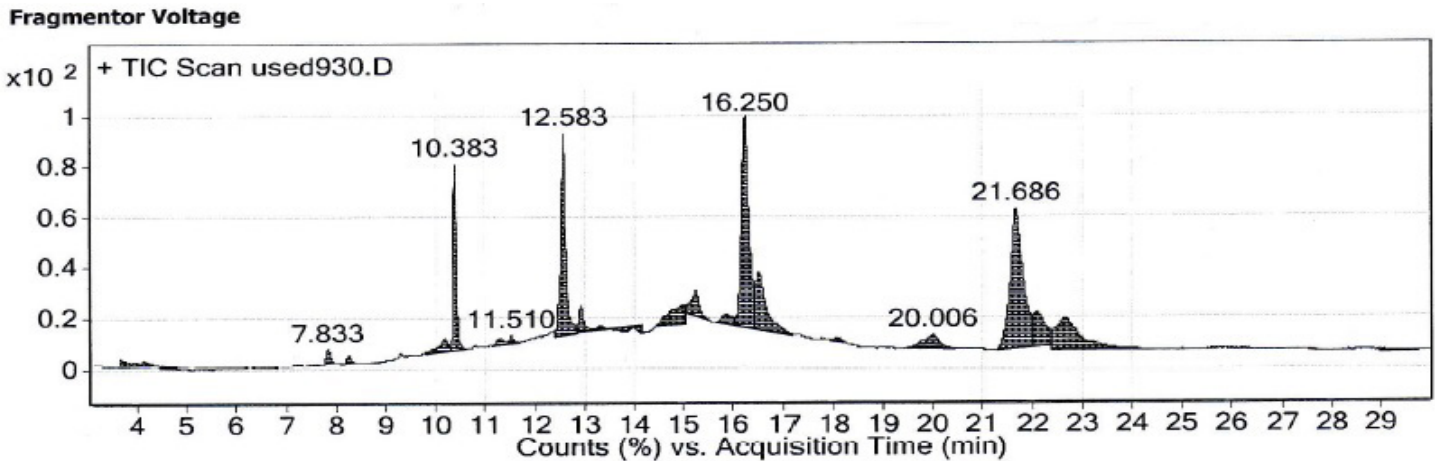

Figure 6: The chromatograms of used cooking oil before transesterification.

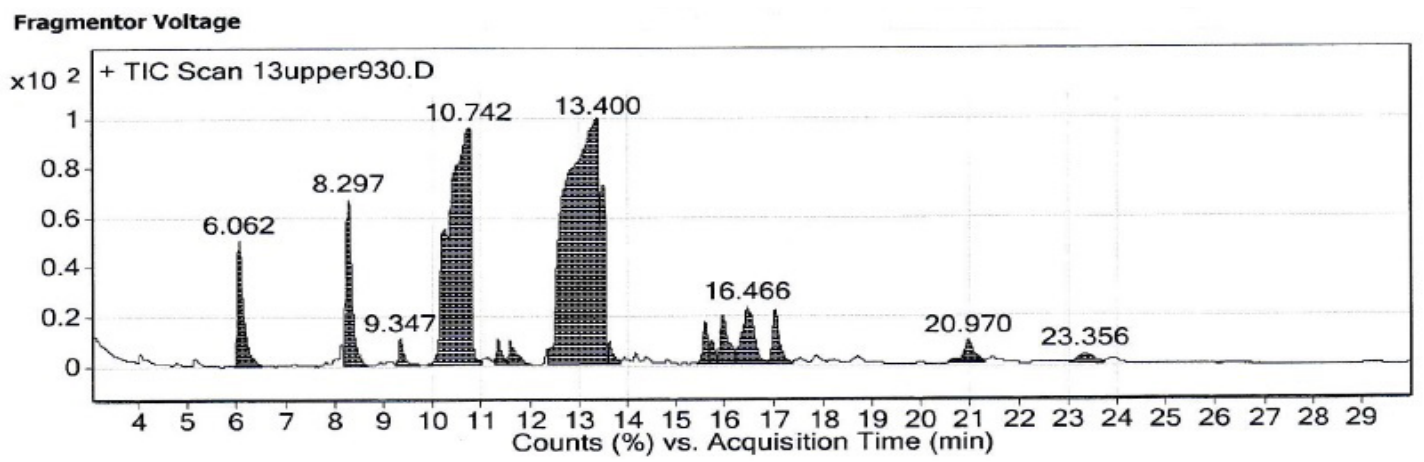

Figure 7: The chromatograms of used cooking oil after transesterification using calcined eggshell.

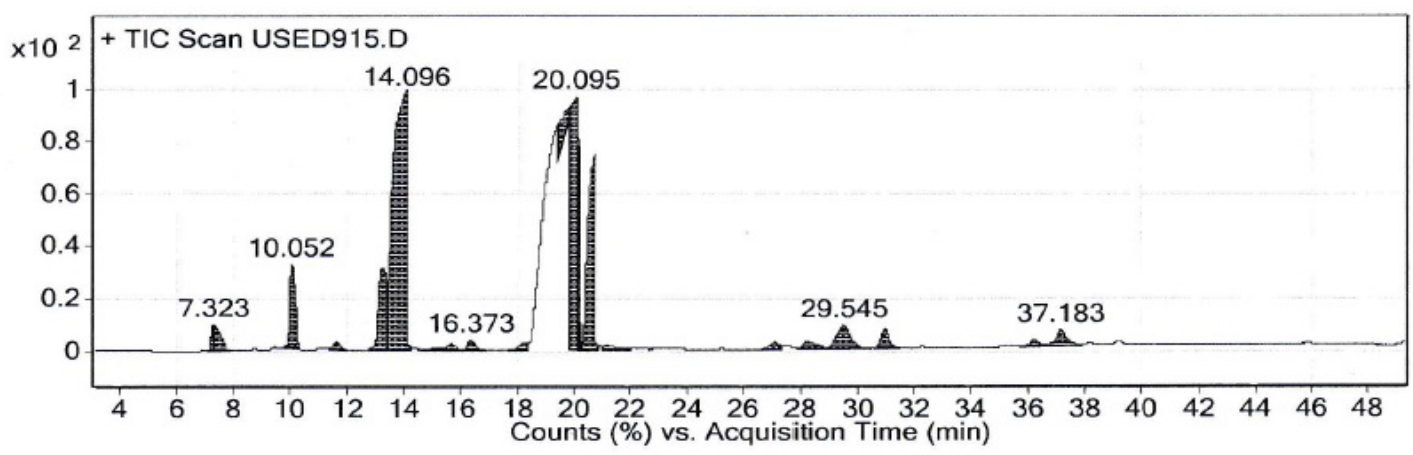

Figure 8: The chromatograms of used cooking oil after transesterification using calcined $\mathrm{CaO}$.

Table 1: GC-MS analysis of sample product using calcined eggshell as the catalyst.

\begin{tabular}{lllll}
\hline No & Systemic name & Common name & Formula & Molecular mass \\
\hline $\mathbf{1}$ & 9- Octadecenoic acid, methyl ester, (E) & Methyl 9-octadecenoate & $\mathrm{C}_{19} \mathrm{H}_{36} \mathrm{O}_{2}$ & 296 \\
$\mathbf{2}$ & Hexadecanoic acid, methyl ester & Methyl palmitate & $\mathrm{C}_{17} \mathrm{H}_{34} \mathrm{O}_{2}$ & 270 \\
$\mathbf{3}$ & Methyl tetradecanoate & Methyl myristate & $\mathrm{C}_{15} \mathrm{H}_{30} \mathrm{O}_{2}$ & 242 \\
\hline
\end{tabular}


Table 2: GC-MS analysis of sample product using calcined $\mathrm{CaO}$ as catalyst.

\begin{tabular}{lllll}
\hline No & Systemic name & Common name & Formula & Molecular mass \\
\hline $\mathbf{1}$ & Hexadecanoic acid, methyl ester & Methyl palmitate & $\mathrm{C}_{17} \mathrm{H}_{34} \mathrm{O}_{2}$ & 270 \\
$\mathbf{2}$ & 9- Octadecenoic acid, methyl ester, (E) & Methyl 9-octadecenoate & $\mathrm{C}_{19} \mathrm{H}_{36} \mathrm{O}_{2}$ & 296 \\
$\mathbf{3}$ & Methyl tetradecanoate & Methyl myristate & $\mathrm{C}_{15} \mathrm{H}_{30} \mathrm{O}_{2}$ & 242 \\
\hline
\end{tabular}
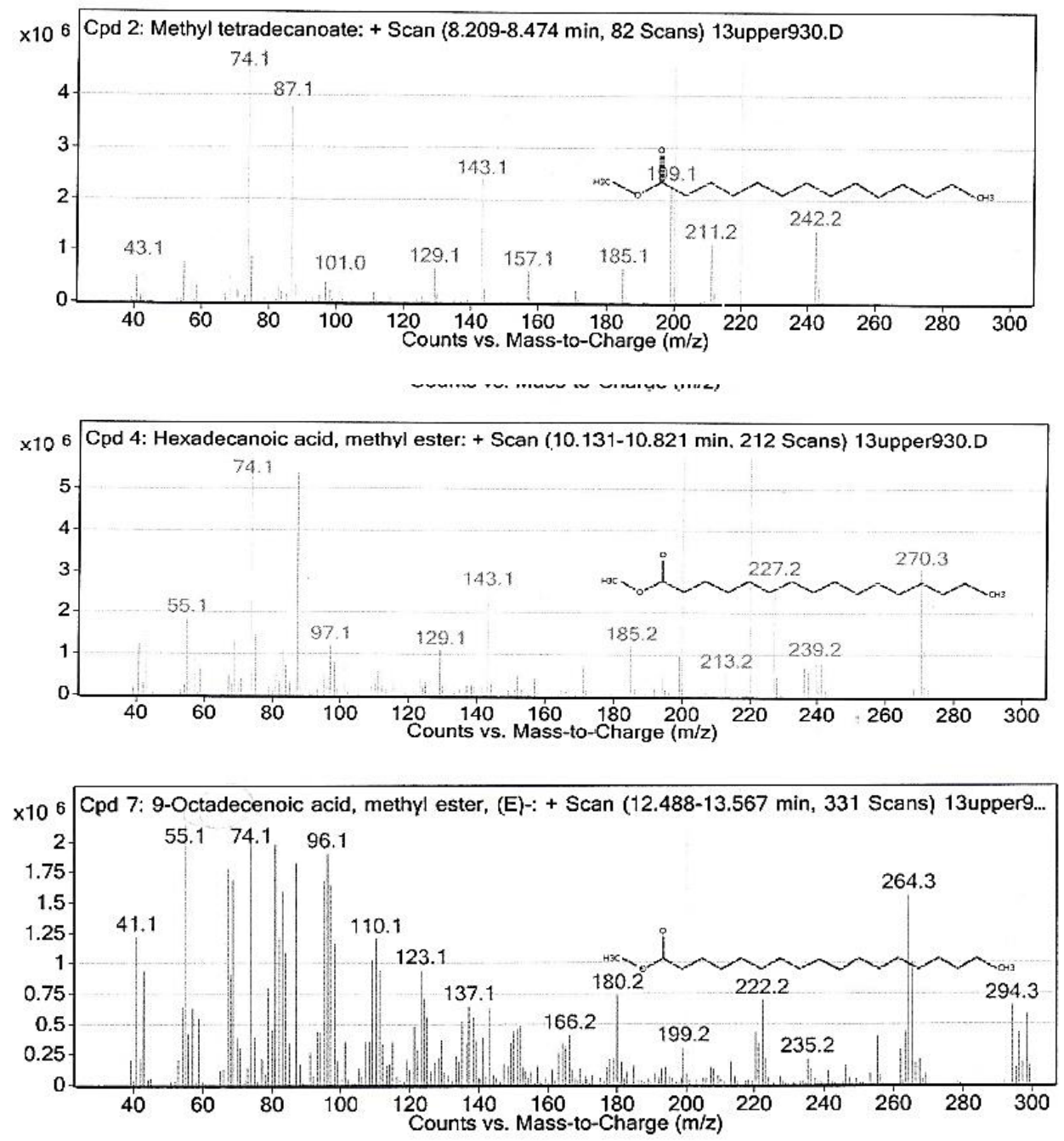

Figure 9:Mas spectrum of selected components after transesterification using calcined eggshell.

The three major components obtained from the mass spectrum analysis report were tabulated accordingly in tables $1 \& 2$. From table 1, methyl 9-octadecenoate, methyl palmitate and methyl myristate were formed as a biodiesel product after transesterification using calcined eggshells. Additionally, table 2 depicted methyl 9-octadecenoate, methyl palmitate and methyl myristate that were formed as a biodiesel product after transesterification using calcined $\mathrm{CaO}$. In brief, the natural eggshells derived $\mathrm{CaO}$ can be used to replace the chemical $\mathrm{CaO}$ in future prospect.

\section{Conclusion}

In this study, different calcination methods on eggshell waste were developed to identify the calcium oxide component that acted as a catalyst and which was used in transesterification. Among different calcination methods, the open air calcination was the best option compared to the nitrogen gas flow method. The formerdid not require an extra cost in purchasing the nitrogen gas. The ggshell derived catalyst consisted only of $\mathrm{CaO}$ as an end product 

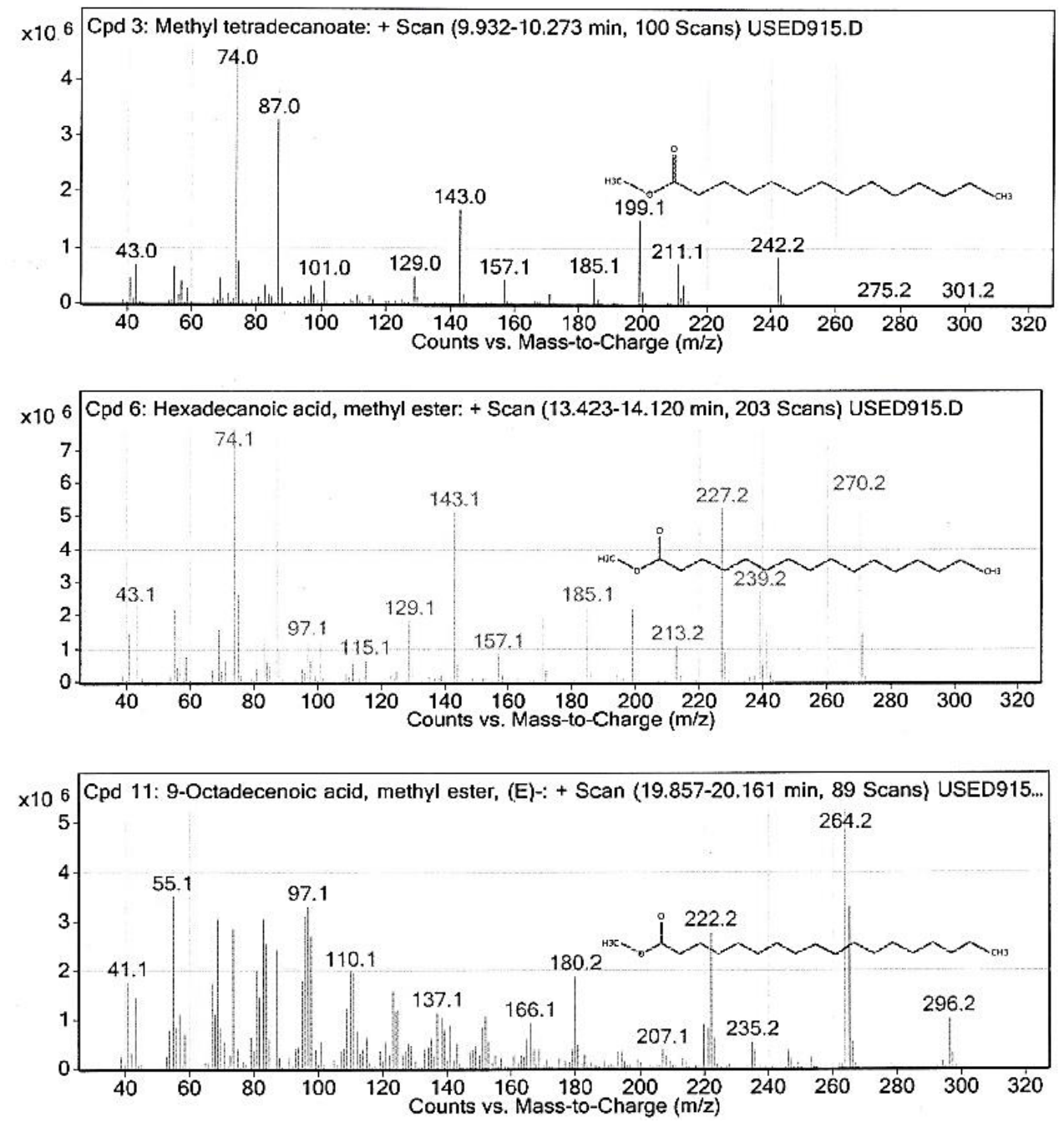

Figure 10:Mass spectrum of selected components after transesterification using calcined $\mathrm{CaO}$.

during the calcination process which was comparable to the calcined pure calcium oxide based on the XRD pattern. The optimal transesterification carried out using calcined eggshells was by the 4:1 methanol to oil ratio, $2 \mathrm{wt} \%$ of catalyst weight and a reaction temperature of $65^{\circ} \mathrm{C}$ for 2 hours. Pure calcined calcium oxide acted as the experimental control and was subjected accordingly to the optimum calcined eggshell parameter. Bothmethyl ester components appeared almost at the same. It can be assumed that the natural derived $\mathrm{CaO}$ was capable of showing its catalytic activities during the transesterification process. Hence, it is assumed that the waste calcined eggshell can be replaced by the chemical calcium oxide. The cost of the biodiesel production could reduce the synthesizing catalyst from the waste materials.
Acknowledgement: The authors express their sincere appreciation to the faculty of Agro Based Industry and the faculty of Bioengineering and Technology, at the Universiti of Malaysia Kelantan, Jeli Campus for the financial support and good facilities which made this study possible.

\section{References}

[1] Abuhabaya, A., Fieldhouse, J., \& Brown, D. (2013). Influence of production variables for biodiesel synthesis on yields and fuel properties, and optimization of production conditions. Fuel, 103, 963-969.

[2] Ho, S.-H., Wong, Y.-D., \& Chang, V. W.-C. (2014). Evaluating the potential of biodiesel (via recycled cooking oil) use in Singapore, an urban city. Resources, Conservation and Recycling, 91, 117-124. 
[3] Sheinbaum-Pardo, C., Calderón-Irazoque, A., \& Ramírez-Suárez, M. (2013). Potential of biodiesel from waste cooking oil in Mexico. Biomass and bioenergy,56, 230-238.

[4] Wei, Z., Xu, C., \& Li, B. (2009). Application of waste eggshell as low-cost solid catalyst for biodiesel production. Bioresource technology, 100(11), 2883-2885.

[5] Sun, D. W. (Ed.). (2011). Handbook of frozen food processing and packaging. CRCPress. 150-288.

[6] Ho, W. F., Hsu, H. C., Hsu, S. K., Hung, C. W., \& Wu, S. C. (2013). Calcium phosphate bioceramics synthesized from eggshell powders through a solid state reaction. Ceramics international, 39(6), 6467-6473.

[7] Noor Idayu, A. (2011). Synthesis Of Hydroxyapatite Powder From Eggshell Waste For Bioceramic Purpose. 20-23.

[8] Guru, P. S., \& Dash, S. (2014). Sorption on eggshell waste-A review on ultrastructure, biomineralization and other applications. Advances in colloid and interface science, 209, 49-67.

[9] Wei, Z., Xu, C., \& Li, B. (2009). Application of waste eggshell as low-cost solid catalyst for biodiesel production. Bioresource technology, 100(11), 2883-2885.

[10] Hattori, H. (2001). Solid base catalysts: generation of basic sites and application to organic synthesis. Applied Catalysis A: General, 222(1), 247-259.

[11] Phan, A. N., \& Phan, T. M. (2008). Biodiesel production from waste cooking oils. Fuel, 87(17), 3490-3496.

[12] Rabu, R. A., Janajreh, I., \& Honnery, D. (2013). Transesterification of waste cooking oil: Process optimization and conversion rate evaluation. Energy Conversion and Management, 65, 764-769.

[13] Mekhilef, S., Siga, S., \& Saidur, R. (2011). A review on palm oil biodiesel as a source of renewable fuel. Renewable and Sustainable Energy Reviews, 15(4), 1937-1949.

[14] Viriya-Empikul, N., Krasae, P., Nualpaeng, W., Yoosuk, B., \& Faungnawakij, K. (2012). Biodiesel production over Ca-based solid catalysts derived from industrial wastes. Fuel, 92(1), 239244.

[15] Tan, Y. H., Abdullah, M. O., Nolasco-Hipolito, C., \& TaufiqYap, Y. H. (2015). Waste ostrich-and chicken-eggshells as heterogeneous base catalyst for biodiesel production from used cooking oil: Catalyst characterization and biodiesel yield performance. Applied Energy, 160, 58-70.

[16] Chen, M., Xiao, F., Putman, B., Leng, B., \& Wu, S. (2014). High temperature properties of rejuvenating recovered binder with rejuvenator, waste cooking and cotton seed oils. Construction and Building Materials, 59, 10-16.

[17] Navajas, A., Issariyakul, T., Arzamendi, G., Gandía, L. M., \& Dalai, A. K. (2013). Development of eggshell derived catalyst for transesterification of used cooking oil for biodiesel production. Asia-Pacific Journal of Chemical Engineering, 8(5), 742-748.

[18] Raihana, M. F., Hamdi, M., \& Ramesh, S. (2008). Novel chemical conversion of eggshell to hydroxyapatite powder. In 4th Kuala Lumpur International Conference on Biomedical Engineering 2008 (pp. 333-336). Springer Berlin Heidelberg.

[19] Jazie, A. A., Pramanik, H., Sinha, A. S. K., \& JAZIE, A. (2013). Egg shell as eco-friendly catalyst for transesterification of rapeseed oil: optimization for biodiesel production. Special Issue of International Journal of Suistanable Development and Green Economics (IJSDGE), 2(1), 27-32.
[20] Buasri, A., Worawanitchaphong, P., Trongyong, S., \& Loryuenyong, V. (2014). Utilization of Scallop Waste Shell for Biodiesel Production from Palm Oil-Optimization Using Taguchi Method. APCBEE Procedia, 8, 216-221.

[21] Viriya-Empikul, N., Krasae, P., Puttasawat, B., Yoosuk, B., Chollacoop, N., \& Faungnawakij, K. (2010). Waste shells of mollusk and egg as biodiesel production catalysts. Bioresource technology, 101(10), 3765-3767.

[22] Fadhil, A. B., Al-Tikrity, E. T., \& Albadree, M. A. (2015). Transesterification of a novel feedstock, Cyprinus carpio fish oil: Influence of co-solvent and characterization of biodiesel. Fuel, 162, 215-223.

[23] Seenuvasan, M., Selvi, P. K., Kumar, M. A., Iyyappan, J., \& Kumar, K. S. (2014). Standardization of non-edible Pongamia pinnata oil methyl ester conversion using hydroxyl content and GC-MS analysis. Journal of the Taiwan Institute of Chemical Engineers, 45(4), 1485-1489.

[24] Zhang, Y., Dube, M. A., McLean, D., \& Kates, M. (2003). Biodiesel production from waste cooking oil: 1 . Process design and technological assessment.Bioresource technology, 89(1),116.

[25] Moradi, G. R., Mohadesi, M., Ghanbari, M., Moradi, M. J., Hosseini, S., \& Davoodbeygi, Y. (2015). Kinetic comparison of two basic heterogenous catalysts obtained from sustainable resources for transesterification of waste cooking oil. 